\title{
VALUE AT RISK: SENSITIVITY TO DIFFERENT ASSET ALLOCATION STRATEGIES DURING RETIREMENT
}

S. P. Uma Rao, D. R. Adhikari ${ }^{1}$ and D. Boudreaux

B.I. Moody III College of Business Administration

University of Louisiana at Lafayette

USA

\section{ABSTRACT}

There is a risk of extreme events in financial markets. This risk is often understated as we have seen in portfolios of subprime mortgages during the 2008 financial crisis. The goal of this study is to draw inferences about the crosssection of VaR estimates for different asset allocation funds.

The study answers this question for 7 different asset allocations 100\% stock (S), 100\% T'bonds (B), 100\% T'bills (or Cash), .4S+.4B+.2Cash, .6S+.4B, .8S+.2B, and .8S+.2Cash. Further, the present study determines that stock-bond-bill asset allocation over a five-year planning period which minimizes VaR while earning a minimum of $7 \%$ return is $72.3 \%$ stocks and $27.7 \%$ bonds.

\section{INTRODUCTION}

\section{SSE 2019 Sensitivity of Value at Risk to different asset allocation Strategies during retirement}

The risk of extreme events is present in financial markets. The potential occurrence of risk events posed by portfolios of subprime mortgages was underestimated during the financial crisis of 2008. The methodology used for the assessment of financial market risk gives the estimation of value at risk (Cerović, 2014). Value at risk (Value-at-risk, or abbreviated VaR) is the maximum-minimum loss of financial position over a given period at a given confidence interval (Jorion, 2007).

Evaluating risk adequately is important for individuals because their portfolio decisions have an impact on their future pensions. Value at Risk ( $\mathrm{VaR}$ ) is a commonly used important measure of risk. Value at risk can be used to quantify the probability and the level of potential loss in a portfolio over some time. Potential retirees can determine whether they have sufficient fund reserves in place to cover possible losses or whether risks require them to reduce portfolio holdings.

Descriptive statistics of data show the presence of fat tails in observed time series, due to skewness and kurtosis, and it is concluded that its empirical distribution deviates from the normal distribution.

When a portfolio deviates from a normal probability distribution, the magnitude of loss and potential for loss may be understated especially when skewness and kurtosis are present.

The paper studies result in the sensitivity of Value at Risk (VaR) to changes in conventional portfolio asset allocation. The purpose of this paper is to estimate Value-at-Risk in each of the assets, such as S\&P500, 3-month Treasury Bills, 10-year Treasury Bonds as well as different portfolios with asset allocations such as $80 \%$ Stock and $20 \%$ Bonds, $60 \%$ Stock and $40 \%$ Bonds, $40 \%$ Stock, $40 \%$ Bonds, and 20\% Cash, $80 \%$ Stock and 20\% Cash, over 1928-2018, a long period that includes years of recession and financial crisis. Portfolio managers use VaR to evaluate the level of risk exposure in a firm or a portfolio.

The paper is organized as follows. A brief literature review is presented in the next section. The third section reviews the methodology used in the VaR calculation. Data and descriptive statistics are given in the fourth section. The fifth section presents empirical results and discussion while the conclusion is presented in the sixth section.

\section{LITERATURE REVIEW}

For a comprehensive overview of Value at Risk and its measures, look at the Jorion, P., 2001, Value at Risk: The New

\footnotetext{
${ }^{1}$ Corresponding Author: Deergha Raj Adhikari, Ph.D., Professor of Economics, B.I. Moody III College of Business Administration, University of Louisiana at Lafayette, USA
} 
Benchmark for Managing Financial Risk, McGraw Hill. For a listing of every possible reference to the measure, try www.GloriaMundi.org. (Also see Hull and White (1998), Engle (2001), Britten-Jones and Schaefer (1999), Rouvinez (1997), Cabedo and I. Moya, 2003, and Hull and White, (1998))

\section{METHODOLOGY}

The value at risk (denoted VaR to distinguish it from Var, the abbreviation for variance) is the loss corresponding to a very low percentile of the entire return distribution, for example, the 5th or 1st percentile return. Practitioners commonly estimate the $5 \% \mathrm{VaR}$, meaning that $95 \%$ of returns will exceed the VaR, and $5 \%$ will be worse. Thus, if the VaR on an asset is $10 \%$ at one-year, $95 \%$ confidence interval, there is only a $5 \%$ chance that the value of the asset will drop more than $10 \%$ over any given year. Therefore, the 5\% VaR may be viewed as the best rate of return out of the 5\% worst-case future scenarios. $\mathrm{VaR}$ is written into the regulation of banks and closely watched by risk managers. VaR can be used by any entity to measure its risk exposure; it is used most often by commercial and investment banks to capture the potential loss in value of their traded portfolios from adverse market movements over a specified period; this can be compared to their available capital and cash reserves to ensure that the losses can be covered without putting the firms at risk. Evaluating risk adequately is important for individuals because their portfolio decisions have an impact on their future pensions. VaR 5\% is the minimum expected loss of $5 \%$ of the time.

\section{Normal Distribution VaR}

When portfolio returns are normally distributed, the VaR is determined by the mean and SD of the distribution. Recalling that approximately -1.65 is the 5 th percentile of the standard normal distribution (with mean $=0$ and $\mathrm{SD}=1$ ), the VaR for a normal distribution is

Normal Distribution VaR with 5 percent can be calculated by using NORMINV built-in function of excel (=Norminv(0.05, average return, standard deviation))

\section{Historical (Sample) VaR}

To obtain a sample estimate of VaR, we sort the observations from high to low. The VaR is the return at the 5th percentile of the sample distribution. Almost always, $5 \%$ of the number of observations will not be an integer, and so we must interpolate.

Here are samples comprises of 91 annual returns so that $5 \%$ of the number of observations is 4.55 . We must interpolate between the fourth and fifth observation from the bottom. Suppose the bottom five returns are:

$1930-0.251236364$ (Bottom 5th)

$1974-0.259017858$ (Bottom 4th)

$1937-0.353367288$ (Bottom 3rd)

$2008-0.365523441$ (Bottom 2nd)

$1931-0.438375489$ (Bottom 1st)

The VaR is, therefore, between $-25.12 \%$ and $-25.9 \%$ and would be calculated as

$\mathrm{VaR}=$ Bottom 4 th return $+0.55 *($ Bottom 5 th return-Bottom 4 th return $)=-25.4738 \%$

\section{Expected Shortfall}

When we assess tail risk by looking at the $5 \%$ worst-case scenarios, the VaR is the most optimistic measure of risk as it takes the highest return (smallest loss) of all these cases. A more realistic view of downside exposure would focus instead on the expected loss given that we find ourselves in one of the worst-case scenarios. Expected Shortfall 5\% is if the worst 5\% comes true, this will be the average loss. This value, unfortunately, has two names: either expected shortfall (ES) or conditional tail expectation (CTE); the latter emphasizes that this expectation is conditioned on being in the left tail of the distribution. ES is the more commonly used terminology.

Extending the previous $\mathrm{VaR}$ example, we assume equal probabilities for all values. Hence, we need to average across the bottom $5 \%$ of the observations. We sum the bottom 4 returns plus 0.55 of the fifth from the bottom and divide by 4.55 to 
find $\mathrm{ES}=-34.2 \%$, significantly less than the $-25.47 \% \mathrm{VaR}$. It is a lot simpler to calculate ES at a $95 \%$ confidence level with an approximation of 5 instead of exact 4.55 by using excel function [=AVERAGE(SMALL(range of 91 observations, $\{1,2,3,4,5\}))]$. By using this approximation, the Expected shortfall for Stocks with a 95\% confidence level is $33.35 \%$.

Determining stock-bond-bill asset allocation over a five-year planning period while minimizing VaR and earning a minimum of $7 \%$ return

\section{Bootstrap Simulations}

One way to learn from history about the distribution of short-term future returns is to simulate these future returns from that history. The method to accomplish this task is called bootstrapping. Bootstrapping is a procedure that avoids any assumptions about the return distribution, except that all rates of return in the sample history are equally likely. For example, we could simulate 5 years of possible future returns by sampling (with replacement) 5 randomly selected annual returns from our available history. We compound those 5 returns to obtain one possible 5-year holding-period return. This procedure is repeated a thousand times to generate a probability distribution of short-term total returns that are anchored in the historical frequency distribution. The cardinal decision when embarking on a bootstrapping exercise is the choice of how far into the past we should go to draw observations for "future" return sequences. We will use the last 30-year historical sample so that we are more likely to include low-probability events of extreme value.

We use bootstrap simulations on asset returns of stocks, t'bonds and t'bills over a five-year planning period. A simulation run is a random sample (with replacement) of 5 years, drawn from the 30 calendar years of 1989 to 2018 . Average returns (standard deviations) for stocks, t'bills and t'bonds were $11.34 \%(17.31 \%), 2.96 \%(2.40 \%)$ and $6.54 \%$ (8.98\%) respectively for this period of thirty years.

We assume Stocks, t'bills and t'bonds do not move independently. In each of the five years, stock, t'bill, and t'bond returns are always chosen from the same row of the data. This enables the bootstrapping approach to reflect the interdependence of the returns on these asset classes exhibited during the past 30 years 1989-2018.

Our simulation approach has an important advantage. Because a simulation run is the same random sample of years for all 3 assets, the simulations capture the cross-correlation of asset returns and its effects on the distribution of VaR estimates. Since we jointly sample asset returns, we also capture any correlated heteroscedasticity of the asset returns and disturbances of an asset allocation model. A random sampling of years in a simulation run preserves the cross-correlation of fund returns, but we lose any effects of autocorrelation. The literature on the autocorrelation of stock returns (e.g., Fama (1965)) suggests that this is a minor problem. We shall see that these details of our approach are important for inferences about true VaR in actual asset returns.

Because of the uncertainty of future returns on these assets, a reasonable approach to asset allocation is to use bootstrapping to generate a thousand simulated values per asset for the planning period of five years and use Solver to solve for the allocation that achieves the expected return while minimizing VaR. Using the last thirty year data from 1989 through 2018, five-year future asset values of stocks, bills, and bonds are calculated for a thousand random scenarios with the help of data tables.

\section{DATA AND DESCRIPTIVE STATISTICS}

Data comes from French data library at http://mba.tuck.dartmouth.edu/pages/faculty/ken.french/data_library.html Descriptive statistics are calculated using Microsoft Excel.

\section{RESULTS AND DISCUSSION}

Table 1 shows the results of Statistics for Asset-class Portfolios for a period of 91-years, 1928-2018. Table 2 shows these same results for the last thirty years, from 1989-2018. This data for the last thirty years was used for bootstrap simulations of 5-year values of stocks, bills, and bonds. The results of the simulations are shown in Table 3 . Important statistics are categorized in panels A, B, C, D and E. Panel A shows the risk-return tradeoff. The only way an investor earns a 
higher return is by taking on more risk in the financial markets. A better measure to evaluate return and risk is the Sharpe Ratio.

\section{A. The Reward to Volatility (Sharpe) Ratio}

Sharpe Ratio $=[$ Risk premium $] /($ SD of excess return $)$

Investors presumably are interested in the expected excess return they can earn by replacing T-bills with a risky portfolio, as well as the risk they would thereby incur. The importance of the trade-off between reward (the risk premium) and risk (as measured by the standard deviation or SD) suggests that we measure the attraction of a portfolio by the ratio of risk premium to $\mathrm{SD}$ of excess returns. Sharpe ratio is the highest $(0.65)$ for the asset allocation of [.4S $+.4 \mathrm{~B}+.2 \mathrm{Cash}]$.

\section{B. Deviation from Normality}

\section{i. Skew}

Skewness measures the asymmetry of a distribution. A distribution is called asymmetric when one tail is longer than the other. If the skewness is positive, then the distribution is skewed to the right while a negative skewness implies a distribution skewed to the left. The skewness for a normal distribution is zero, and any symmetric data should have skewness near zero. When the distribution is positively skewed, the standard deviation overestimates the risk.

Conversely, and more importantly, when the distribution is negatively skewed, the standard deviation will underestimate the risk. A measure of asymmetry called skew uses the ratio of the average cubed deviations from the average, called the third moment, to the cubed standard deviation to measure asymmetry or "skewness" of a distribution.

$$
\text { Skew }=\text { Average }\left[\frac{\left(R-\overline{R)^{3}}\right.}{\sigma^{3}}\right]
$$

Table 1 shows that Skewness for different allocations ranges from -.42 for $80 \%$ Stock and 20\% Cash to 1.03 for $100 \%$ Cash. If the absolute value of the skewness for the data is more than twice the standard error this indicates that the data are not symmetric, and therefore not normal. The data are not symmetric in the case of $100 \%$ Cash and 100\% Bonds.

\section{ii. Kurtosis}

Kurtosis measures the degree of fat tails. We use deviations from the average raised to the fourth power, scaled by the fourth power of the SD.

$$
\text { Kurtosis }=\text { Average }\left[\frac{(R-\bar{R})^{4}}{\sigma^{4}}\right]-3
$$

We subtract 3 in the above Equation because the ratio for a normal distribution is 3. Thus, the kurtosis of a normal distribution is defined as zero, and any kurtosis above zero is a sign of fatter tails. Table 1 show that Kurtosis for different allocations ranges from .08 for $80 \%$ Stock and $20 \%$ Bonds to 1.73 for $100 \%$ Bonds. If the absolute value of the kurtosis for the data is more than twice the standard error this is also an indication that the data are not normal.

Only $100 \%$ Cash and $100 \%$ Bond data are not normal. The values for asymmetry and kurtosis between -2 and +2 are considered acceptable in order to prove normal univariate distribution (George \& Mallery, 2010).

A higher frequency of extreme negative returns may result from negative skew and/or kurtosis (fat tails). Therefore, we would like a risk measure that indicates vulnerability to extreme negative returns. We discuss two such measures that are most frequently used in practice: value at risk and expected shortfall.

\section{Normal Distribution VaR}

We calculate VaR assuming a normal distribution of returns. It is $-20.85 \%$ for Stocks. 


\section{Historical VaR}

We also calculate historical (or sample) Value at Risk (VaR) for portfolios with different asset allocations using historical data of S\&P 500, 10-year T'bonds, and 3-month T-bills for a period of ninety-one years from 1928-2018. Historical $\mathrm{VaR}$ for Stocks is $-\mathbf{2 5 . 4 7 \%}$. Notice the output is different for Normal distribution VaR and historical VaR for Stocks. The reason is that the two formulas would only match if the data set was perfectly normal.

\section{E. Expected Shortfall}

We calculate Expected Shortfall (or Conditional Value at Risk CVaR ) for portfolios with different asset allocations for the period 1928-2018. Conditional Value at Risk (CVaR) or Expected Shortfall can be a more accurate measure of risk. Conditional Value at Risk will give us an average expected loss and take into account more contingencies.

This expected shortfall for stocks with a $95 \%$ confidence level is $-33.35 \%$.

\section{Limitations of VaR}

While Value at Risk has acquired a strong following in the risk management community, there is reason to be skeptical of both its accuracy as a risk management tool and its use in decision making. VaR can be wrong. There is no precise measure of Value at Risk, and each measure comes with its own limitations. The end result is that the Value at Risk that we compute for an asset, portfolio or firm can be wrong, and sometimes, the errors can be large enough to make VaR a misleading measure of risk exposure. The reasons for the errors can vary across assets and for different measures and include the following.

Return distributions: Every VaR measure makes assumptions about return distributions, which, if violated, result in incorrect estimates of the Value at Risk. With delta-normal estimates of VaR, we are assuming that the multivariate return distribution is the normal distribution since the Value at Risk is based entirely on the standard deviation in returns. With historical simulations, we are assuming that the historical return distribution (based upon past data) is representative of the distribution of returns looking forward. There is substantial evidence that returns are not normally distributed and that not only are outliers more common in reality but that they are much larger than expected, given the normal distribution. Value at Risk measure will be a function of the time period over which the historical data is collected. If that time period was a relatively stable one, the computed Value at Risk will be a low number and will understate the risk looking forward. Conversely, if the time period examined was volatile, the Value at Risk will be set too high.

\section{Bootstrap Simulations}

Using a 5-year planning horizon, optimum allocation of an investment portfolio -between stocks, treasury bills and treasury bonds- that yields a minimum $\mathrm{VaR}$ and provides expected return of at least $7 \%$.

This study finds that at a minimized Value at Risk of $.025 \%$, the asset allocation is $72.3 \%$ stocks and $27.7 \%$ bonds. The portfolio yields an expected annual return of $9.76 \%$ at an annual standard deviation of $5.8 \%$. If a dollar is invested in the portfolio, the final value at the end of five years is expected to be $\$ 1.6382 .95 \%$ of the final value at the end of five years will be more than $\$ 1.00126$.

\section{CONCLUSION}

There is a risk of extreme events in financial markets. This risk is often understated as we have seen in portfolios of subprime mortgages during the 2008 financial crisis. There is evidence that the returns are not normally distributed. Whenever there is a deviation from normality, outliers are much larger than expected, given the normal distribution.

A newer measure that has gained prominence in recent decades ignores potential gains and looks at downside risk. That measure, called "value at risk," tells the investor that he has a 5\% chance of losing $10 \%$ or more in a year, but it doesn't zero in on the worst downside scenarios.

To focus on extreme risk, many firms have begun using a measure called "expected shortfall" or "conditional value at risk," which is the expected portfolio loss when the value at risk has been breached. Conditional Value at risk helps estimate the magnitudes of expected loss on the very bad years. Firms such as J.P. Morgan and MSCI Barra are employing the measure. The goal of this study is to draw inferences about the cross-section of VaR estimates for different asset allocation funds. The study answers this question for 7 different asset allocations 100\% stock (S), 100\% T'bonds (B), 100\% T'bills (or Cash), 

over a five-year planning period which minimizes VaR while earning a minimum of $7 \%$ return is $72.3 \%$ stocks and $27.7 \%$ bonds.

\section{REFERENCES}

Berstein Solange M. Rómulo A. Chumacero. VaR Limits for Pension Funds: An Evaluation. April 2010. https://mpra.ub.uni-muenchen.de/22574/1/MPRA_paper_22574.pdf

Britten-Jones, M. and Schaefer, S.M., 1999, Non-linear value-at-risk, European Finance Review, v2, 161-187;

Cabedo, J.D. and I. Moya, 2003, Estimating oil price Value at Risk using the historical simulation approach, Energy Economics, v25, 239-253.

Cerović, J. (2014), "Value at risk measuring and Extreme value theory: Evidence from Montenegro", Facta Universitatis, Series: Economics and Organization, Vol. 11, No. 2, pp. 175-189.

Engle, R., 2001, Garch 101: The Use of ARCH and GARCH models in Applied Econometrics, Journal of Economic Perspectives, v15, 157-168.

Fama, Eugene F., 1965, The behavior of stock market prices, Journal of Business 38, 34-105.

George, D., \& Mallery, M. (2010). SPSS for Windows Step by Step: A Simple Guide and Reference, 17.0 update (10a ed.) Boston: Pearson.

Hull, J. and A. White, 1998, Value at Risk when daily changes are not normally distributed, Journal of Derivatives, v5, 9-19. Hull, J. and A. White, 1998, Incorporating Volatility Updating into the Historical Simulation Method for Value at Risk, Journal of Risk, v1, 5-19.

Jorion, P. (2007). Value at Risk: The New Benchmark for Managing Financial Risk, 3rd ed., New York: McGraw-Hill. https://www.degruyter.com/downloadpdf/j/bsrj.2015.6.issue-1/bsrj-2015-0003/bsrj-2015-0003.pdf

Value at Risk (VaR) - NYU Stern http://people.stern.nyu.edu/adamodar/pdfiles/papers/VAR.pdf Microsoft@ Office Excel® 2007: Data Analysis and Business Modeling, Second Edition by Wayne L. Winston Chapter 62.

Microsoft® Excel® 2010: Data Analysis and Business Modeling by Wayne L. Winston. Chapter 68.

Microsoft Excel 2013: Data Analysis and Business Modeling https://ptgmedia.pearsoncmg.com/images/9780735669130/.../9780735669130.pdf

Chapter 75 Simulating stock prices and asset allocation modeling pp. 721

Rouvinez, C. , 1997, Going Greek with VAR, Risk, v10, 57-65.

https://programmingforfinance.com/2017/10/calculating-value-at-risk-var-multiple-approaches/ 
E-ISSN: 2469-6501

VOL: 6, ISSUE: 2

February/2020

DOI:10.33642/fjbass.v6n2p7

https://ijbassnet.com/

\section{(C) Center for Promoting Education and Research (CPER) USA}

WWW.cpernet.org

Table 1: Statistics for Asset-class Portfolios, 1928-2018 (Annual rates in U.S. Dollars, \%)

1928 through 2018

years (a total 91 years)

A. Return, Risk, pe Ratio

Average Return

Standard deviation

Worst Loss (return)

\# Years with Loss

Prob. of loss

Sharpe

Ratio=reward/volatility

B. Deviation from

Normality

\section{Skew}

Kurtosis

\section{Normal}

Distribution VaR with

5 percent using

NORMINV

\begin{tabular}{|c|c|c|c|c|c|c|}
\hline S for Stock & $\begin{array}{l}\text { T for T'bills } \\
\text { (or Cash) }\end{array}$ & B for T'bonds & $\begin{array}{l}.4 \mathrm{~S}+.4 \mathrm{~B}+.2 \mathrm{Cash} \\
\text { Portfolio }\end{array}$ & $\begin{array}{l}.6 \mathrm{~S}+.4 \mathrm{~B} \\
\text { Portfolio }\end{array}$ & $\begin{array}{r}.8 S+.2 B \\
\text { Portfolio }\end{array}$ & $\begin{array}{l}.8 \mathrm{~S}+.2 \text { Cash } \\
\text { Portfolio }\end{array}$ \\
\hline
\end{tabular}

\begin{tabular}{|c|c|c|}
\hline & 3-month & 10-year T' \\
\hline S\&P 500 & T’Bill & Bond \\
\hline
\end{tabular}

$11.36 \% \quad 3.43 \% \quad 5.10 \%$

$0.19581618 \quad 0.030399717$

0.076993745

$-11.12 \%$

$-43.84 \%$

$0.03 \%$

17

0.28409091

0.193181818

0.217083882
$7.27 \%$

0.084278774

$-18.10 \%$

19

0.215909091

0.455719017
Portfolio

$10.10 \%$

0.15707832

$-35.58 \%$

24

0.227272727

0.449176972

0.27272727

0.42517912
$9.77 \%$

0.15660927

$-34.61 \%$

25

0.28409091

0.40510756

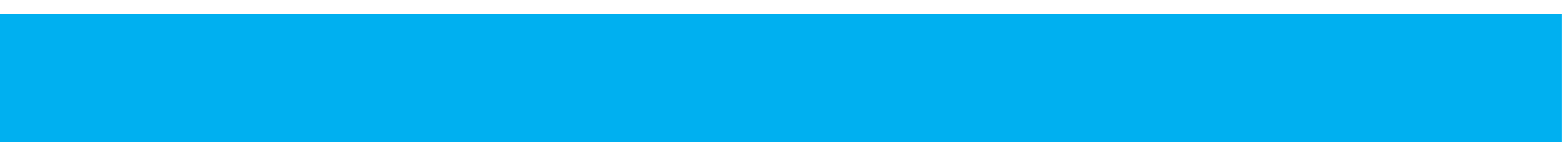

\section{Historical VaR 5\%}

\begin{tabular}{|c|c|c|c|c|c|c|c|}
\hline$n$, No. of returns & 91 & 91 & 91 & 91 & 91 & 91 & 91 \\
\hline Bottom 5\% & $\begin{array}{l}4.55 \text { th } \\
\text { return }\end{array}$ & & 4.55th return & 4.55th return & 4.55th return & $\begin{array}{l}\text { 4.55th } \\
\text { return }\end{array}$ & 4.55th return \\
\hline Bottom 5th return & -0.2512364 & & -0.050140493 & -0.062634257 & -0.13257809 & -0.1919072 & -0.19165929 \\
\hline Bottom 4th return & -0.2590179 & & -0.080366556 & -0.07323082 & -0.13890894 & -0.2032370 & -0.19188909 \\
\hline Bottom 4.55th return & -0.254738 & & -0.063742221 & -0.06740271 & -0.13542697 & -0.1970056 & -0.1917627 \\
\hline
\end{tabular}

\section{E. ES (Expected}

Shortfall)

$95 \%$ confidence 
E-ISSN: 2469-6501

VOL: 6, ISSUE: 2

February/2020

DOI:10.33642/fjbass.v6n2p7

https://ijbassnet.com/

\section{(C) Center for Promoting Education and Research (CPER) USA}

WWW.cpernet.org

Table 2: Statistics for Asset-class Portfolios, 1989-2018 (Annual rates in U.S. Dollars, \%) 1928 through 2018 years (a total 91 years)

S for Stock

A. Return, Risk, Sharpe Ratio

Average Return

Standard deviation

Worst Loss (return)

\# Years with Loss

Prob. of loss

Sharpe

Ratio=reward/volatility

B. Deviation from

Normality

Skew

Kurtosis

0.17315268

0.48417381

$-0.7807612$

0.66674739

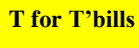

(or Cash)

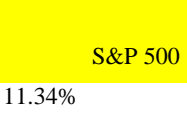

$0.03 \%$
0.348283319

$-0.89195711$
$-11.12 \%$

$-13.89 \%$

5

0.1666666667

0.166666667

$0.398609709 \quad 0.650884684$

0.47355437

0.259490911
$-0.193031854$

$-0.555124914$
B for T'bonds

$.4 \mathrm{~S}+.4 \mathrm{~B}+.2 \mathrm{Cash}$

Portfolio

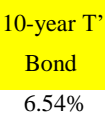

0.089820881

0.073524217

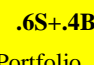

.8S+.2B

Portfolio

$10.38 \%$

$9.66 \%$

0.103503799

0.13637049

0.13928874

0.624353746

0.54432221

0.48150909
$-28.92 \%$

0.2
$-0.0051082$

0.062234815
$-0.5298404$

$-0.75946607$

0.70273476
C. Normal

Distribution VaR with

5 percent

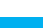

\section{Historical VaR 5\% \\ N, No. of returns \\ Bottom 5\%}

Bottom2nd return

Bottom1st return

Bottom 1.5th return (i.e. historical VaR

5\%)
1.5 th return

$-0.2196605$

$-0.3655234$

$-0.292592$ 1.5th return

$-0.091045688$

$-0.111166953$

$-0.101106321$
$-0.043521121$

(


E-ISSN: 2469-6501

VOL: 6, ISSUE: 2

February/2020

DOI:10.33642/ijbass.v6n2p7

https://ijbassnet.com/

\section{(C) Center for Promoting Education and Research (CPER) USA}

WwW.cpernet.org

i (Expected

fall)

95\% confidence

$-0.292592$

$-0.101106321$

$-0.043358924$

$-0.10511981$

$-0.1988558$

$-0.23083107$

\section{Table 3: Bootstrap-Simulated 5-year Return and measures for non-normal distributions}

Results of 1000 simulated values for stocks, t'bills and t'bonds in 5years. (Assume each asset class has initial price of $\$ 1$ ).

Trial asset allocation:

Stocks: 0.4

Bills: .2

Bonds: .4

\section{Mean return $=\mathbf{0 . 0 7 6 1 5}$}

Standard. deviation $=\quad \mathbf{0 . 0 3 5 8}$

$5 \%$ Value at Risk $=\mathbf{0 . 0 2 1 7 3}$

Average 5- year annually

compounded final value of the

$$
\text { portfolio }=\mathbf{1 . 4 5 9 4 8}
$$

5-year planning horizon: Optimal Asset allocation

Portfolio between stocks, treasury bills and treasury bonds.

When VaR was minimized with (1) changing variable cells to the allocation of assets and (2) three constraints-

each asset $>=0$, total allocation in assets is

of portfolio $>7 \%$ ) and (3) making unconstrained variables non-

negativ

The Optimum Allocation was:

Stock $\quad 151$

Bills 005

Bonds .276849

Mean $=.09757$ (constraint was that it should be greater

Standard dev. $=.05844$

$5 \%$ Value at Risk $=.00025$ (Minimized);

Avg. 5-year annually compounded final value of the portfolio = of investment relat

(allocation in $100 \%$ and mean

Return than $7 \%$ )
$95 \%$ of the final value at the end of five years will be more $\$ 1.00126$ 